\title{
Noncooperative collusion and price wars with individual demand fluctuations
}

Citation for published version (APA):

Pot, E. A., Peeters, R. J. A. P., Peters, H. J. M., \& Vermeulen, A. J. (2008). Noncooperative collusion and price wars with individual demand fluctuations. METEOR, Maastricht University School of Business and Economics. METEOR Research Memorandum No. 017 https://doi.org/10.26481/umamet.2008017

Document status and date:

Published: 01/01/2008

DOI:

10.26481/umamet.2008017

Document Version:

Publisher's PDF, also known as Version of record

\section{Please check the document version of this publication:}

- A submitted manuscript is the version of the article upon submission and before peer-review. There can be important differences between the submitted version and the official published version of record.

People interested in the research are advised to contact the author for the final version of the publication, or visit the DOI to the publisher's website.

- The final author version and the galley proof are versions of the publication after peer review.

- The final published version features the final layout of the paper including the volume, issue and page numbers.

Link to publication

\footnotetext{
General rights rights.

- You may freely distribute the URL identifying the publication in the public portal. please follow below link for the End User Agreement:

www.umlib.nl/taverne-license

Take down policy

If you believe that this document breaches copyright please contact us at:

repository@maastrichtuniversity.nl

providing details and we will investigate your claim.
}

Copyright and moral rights for the publications made accessible in the public portal are retained by the authors and/or other copyright owners and it is a condition of accessing publications that users recognise and abide by the legal requirements associated with these

- Users may download and print one copy of any publication from the public portal for the purpose of private study or research.

- You may not further distribute the material or use it for any profit-making activity or commercial gain

If the publication is distributed under the terms of Article $25 \mathrm{fa}$ of the Dutch Copyright Act, indicated by the "Taverne" license above, 
Erik Pot, Ronald Peeters, Hans Peters, Dries Vermeulen

Noncooperative Collusion and Price Wars with Individual Demand Fluctuations

$\mathrm{RM} / 08 / 017$

JEL code: C73, D43, L13

\section{METE@R}

Maastricht research school of Economics of TEchnology and ORganizations

Universiteit Maastricht

Faculty of Economics and Business Administration P.O. Box 616

NL - 6200 MD Maastricht

phone : ++31 433883830

fax : ++31433884873 


\title{
Noncooperative Collusion and Price Wars with Individual Demand Fluctuations
}

\author{
Erik Pot, ${ }^{1}$ Ronald Peeters, ${ }^{2}$ Hans Peters, ${ }^{3}$ and Dries Vermeulen ${ }^{4}$
}

\begin{abstract}
We analyze whether noncooperative collusive equilibria are harder to sustain when individual demand levels are not fixed but are able to fluctuate. To do this, we extend a Bertrand-type model of price competition to allow for fluctuating market shares when prices are equal. We find that, the larger the market share fluctuations may be, the higher the discount factor should be to sustain a collusive equilibrium in trigger strategies. The intuition behind this is fairly straightforward. When individual demand in the collusive state is suddenly low, the gains from collusion go down. Moreover, the firm with the low demand can capture a larger share of the market by deviating from the collusive strategy. The incentive to deviate therefore becomes larger when the individual market share decreases. We also look at the existence of a specific type of semi-collusive equilibrium when individual market shares are either common knowledge or private knowledge. We find that there exist equilibria in which competitive periods (price wars) occur with probability 1 and on the equilibrium path.
\end{abstract}

Keywords and Phrases: Noncooperative collusion, price wars, repeated games.

JEL Classification Numbers: C73, D43, L13.

\footnotetext{
${ }^{1}$ e.pot@ke.unimaas.nl. Department of Quantitative Economics, Maastricht University, P.O. Box 616, 6200 MD Maastricht, The Netherlands.

${ }^{2}$ r.peeters@algec.unimaas.nl. Department of Economics, Maastricht University, P.O. Box 616, 6200 MD Maastricht, The Netherlands.

${ }^{3}$ h.peters@ke.unimaas.nl. Department of Quantitative Economics, Maastricht University, P.O. Box 616, 6200 MD Maastricht, The Netherlands.

${ }^{4}$ d.vermeulen@ke.unimaas.nl. Department of Quantitative Economics, Maastricht University, P.O. Box 616, 6200 MD Maastricht, The Netherlands.
} 


\section{Introduction}

This paper is a contribution to the longstanding debate on the stability of (tacit) collusion among oligopolists and the existence of price wars on the equilibrium path. In particular, we look at the effects that fluctuations in market shares of individual firms (i.e. individual demand level) might have. We allow for exogenous influences on the respective market shares of the firms in the market and model this using a dynamic game including a stochastic process that determines the realization of the individual market shares in each period. Firms in this model are typically asymmetric in individual demand within a certain period while they face the decision to act collusively or competitively in the presence of uncertainty about future payoffs and, possibly, about the exact situation their competitors are in.

It is well known in the industrial organization literature that (market) demand levels can play an important role in the stability of collusion and the occurrence of price wars (see for instance Green and Porter (1984) and Rotemberg and Saloner (1986)). In our paper however, we look at individual demand fluctuations, keeping overall market demand constant. We find that in our model, collusion is harder to sustain when the possibility exists that the market share of a particular firm is relatively low. The intuition behind this effect is fairly simple. When a firm faces low individual demand, the rewards for breaking the collusive agreement are relatively high (since it can capture a larger portion of the market). In addition, when the firm also expects its demand to be low in the future, the punishment ensuing the breaking of the agreement is relatively smaller. Therefore, the incentives to terminate collusive behavior are larger in periods of low individual demand than in periods of high individual demand. Furthermore, when firms possess private information about their individual demand level, the market as a whole cannot decrease these incentives in a similar manner as in Rotemberg and Saloner (1986) - by decreasing the collusive price in periods where the incentive to deviate is high - although they can when there is full information on market shares.

The article is organized as follows. In Section 2 we present and briefly discuss the existing literature on tacitly collusive behavior and the occurrence of price wars on or off the equilibrium path. Section 3 presents our model and explains the assumptions underlying this model. In Section 4 we prove that a collusive equilibrium in trigger strategies is harder to sustain in the presence of market share fluctuations. In Section 5 we show that firms can reduce the temptation to deviate by cutting their price in periods in which a firm has a low market share. In Section 6 we show that equilibria exist in which firms act collusively as long as their market shares are above a certain threshold. Section 7 discusses the results. 


\section{Literature}

Although the topics of tacit collusion and price wars (in equilibrium) have enjoyed quite some attention in the literature over the last few decades, the focus has largely been on symmetric models in which the incentives to deviate from the collusive agreement are similar for all firms. The existing literature on the topic can be divided into a few categories.

In the first category, firms cannot directly observe their opponents' behavior. A drop in one's own performance will then be interpreted as being caused by a secret deviation from collusive behavior by one of the opponents. In these models, a price war is seen as the reversion from cooperative pricing to non-cooperative behavior which occurs as a reaction to such deviations from the collusive agreement. The root of this branch of literature can be traced to Stigler (1964). However, in his model we should not expect to see price wars ever happening in reality, because a rational firm would avoid getting accused of deviating. The first paper that showed that price wars can occur on an equilibrium path in these kinds of models is Green and Porter (1984). In their model, periods of worse performance can occur as a result of deviating behavior of one of the firms or because of low demand in the market. Since firms are unable to distinguish between these two scenarios, they have to show retaliatory behavior in any case, to discourage deviating behavior in the future. Price wars will thus occur with certainty in periods of low demand, even though no deviation has taken place. Firm-optimal equilibria in this model have been presented in Porter (1983a) and Abreu, Pearce and Stacchetti (1986). Although the Green and Porter (1984) model provides a very good explanation for the occurrence of price wars, it does not apply to price wars that were consciously started by a single firm. In the model's equilibrium, price wars only occur because of a period of low demand and never because of deviating behavior by one of the firms in the market.

Although Green and Porter (1984) show price wars in periods of low demand (recessions), the second category of literature focuses on price wars in periods of high demand (booms). An important contribution in the mid-80s came from Rotemberg and Saloner (1986), who show that collusion is under greater pressure during booms since firms have more to gain from deviating behavior in such a period. The temptation for all firms to attract an unusually high level of demand during a boom outweighs the lower relative profit it would get during the ensuing price war. To avoid this, we would see gradual and coordinated adjustment of the price level to the level of demand. This can however hardly be called a price war, since these actions are taken jointly with the competitors as part of a collusive agreement. This was concisely put by Ellison (1994): "Rotemberg and Saloner (1986), is commonly associated with the statement that price 
wars are more likely to occur during booms, and therefore viewed as somehow in opposition to the Green and Porter theory. The actual Rotemberg and Saloner model, however, is really about countercyclical pricing - firms have perfect information and adjust prices smoothly in response to demand conditions." Rotemberg and Saloner's (1986) model of countercyclical pricing behavior has been extended on numerous occasions to allow for more realistic business cycle characteristics. As in Rotemberg and Saloner (1986) firms only experience i.i.d. demand shocks, the realization of today's demand level contains no information about tomorrow's expected demand level. Kandori (1991) therefore introduces Markovian demand shocks into the model, while Haltiwanger and Harrington (1991) specify a demand function that is cyclically moving over time. Bagwell and Staiger (1997) instead assume that the level of market demand alternates stochastically between slow- and fast-growth states. Variations of another nature have been proposed by Athey, Bagwell and Sanchirico (2004), who assume private cost information and by Leufkens and Peeters (2008), who use an alternating move game to confirm Rotemberg and Saloner's (1986) finding that countercyclical price (war) behavior can occur in periods of high market demand.

A third branch of literature focuses on the role of capacity constraints and investments. Important are the contributions by Klemperer $(1989,1995)$, Staiger and Wolak (1992), who introduce a capacity-setting stage at the beginning of each period in a model based on that of Rotemberg and Saloner (1986), and Wilson and Reynolds (2005).

Other analyses of price wars have been offered by Eckert (2004), who investigates a price-setting alternating move game with differentiated products and by Slade (1989), who has focused on price wars as opportunities for firms to learn about unknown or changed market circumstances. Finally, Fershtman and Pakes (2000) show that non-cooperative behavior can sometimes be caused by predatory behavior: trying to force one's opponent out of the market.

In the empirical literature on price wars, both Green and Porter's (1984) as Rotemberg and Saloner's (1986) model have been critically tested and compared. Relevant empirical papers include Porter (1983b) and Porter (1985), in which the author provides empirical support for the theoretical model of the Green and Porter (1984) model. Brander and Zhang (1993) also find some support for a 'Green and Porter'-type of quantity setting regime switching behavior in the airline industry, as does Levenstein's (1997) study of the bromine industry. On the other hand, Domowitz, Hubbard and Petersen (1987) find some empirical support for the Rotemberg and Saloner (1986) model, which however could not be agreed upon by Ellison (1994), who finds little support for Rotemberg and Saloner (1986) in a study of the Joint Executive Committee. 
In short, no conclusive support for either of the two models has yet been given.

\section{Basic model}

In this section we present the basic model we use in our analysis. In the model, customers care primarily about price and will therefore always prefer the lowest-priced products. However, when there are more firms with the same lowest price, these firms do not necessarily divide the total demand equally. The rationale behind this is that consumers, although primarily interested in price level, might be flexible in their choice of product once they are price-indifferent between alternatives. Consequently, consumers do not necessarily buy the product from the same producer in each period.

\subsection{The one shot game}

The one shot game is based on a Bertrand model in which $n$ firms compete on price in a market for a homogeneous good. All firms have the same constant marginal cost $c$. In the one shot game each firm has three actions it could possibly take, namely to collude $(C)$, to undercut $(U)$, or to choose price equal to marginal cost $(M)$. Thus, each firm chooses an action $a_{i} \in\{U, C, M\}$ without prior information on the choices of the other firms. A second ingredient of the model is a vector $\varphi=\left(\varphi_{1}, \ldots, \varphi_{n}\right)$ of market shares, where $\varphi_{i} \geq 0$ represents the market share of firm $i$. The market share vector prescribes how total profits are divided among firms that choose the same action. Market shares divide the total market, so $\sum_{i} \varphi_{i}=1$.

Profits are now determined as follows. Given a profile $a=\left(a_{i}\right)_{i \in N}$ of chosen actions, the resulting profit of firm $i$ is denoted by $\Pi_{i}(a)$. When $a_{i}=C$ for all $i$, then $\Pi_{i}(a)=\varphi_{i} \Pi$, where $\Pi$ represents the monopoly profit in the market. Thus, in this case, firms act monopolistically and profits are divided according to market share. When there is a firm $k$ with $a_{k}=U$ and $a_{i}=C$ for all $i \neq k$, then $\Pi_{k}(a)=\Pi$ and $\Pi_{i}(a)=0$ for all $i \neq k$. In all other cases all profits are zero.

Remarks. Although our model is based on the model of Bertrand competition, it obviously deviates from the standard approach in modeling Bertrand competition in two aspects.

(1) Our approach starts with the observation that, even though in the original model each firm can choose any price, only three strategies for price setting are relevant for the dynamics of the Bertrand model. These three choices are (a) collusive (monopoly) pricing, (b) price setting slightly below collusive pricing to exploit collusive behavior and to capture the market, and 
(c) competitive (marginal cost) pricing. In our approach we discard other possible choices and only focus on these three crucial price setting strategies. That way we try to keep the analysis of the one shot game simple while we preserve the essential ingredients of the Bertrand model.

(2) Regarding our choice of the payoffs in the one shot model, it is clear that profits are zero when at least one of the firms chooses to use marginal cost pricing. The firm that uses this action attracts the market, but does not make any profit, while the other firms do not have any customers. However, one might assume that firms that undercut the collusive price take their share of the monopoly profit. For simplicity we assume that all profits are zero when more than one firm chooses to undercut while the other firms chose to collude. When at least two firms try to undercut the market the result is a sequence of decreases in price that converges to marginal price setting. This "dynamic process" is captured implicitly in our choice of payoffs. EQUILIBRIUM ANALYSIS OF THE ONE SHOT GAME The one shot game has several Nash equilibria. Evidently the action profile in which all firms play $M$ is a Nash equilibrium. However, when there are at least three firms, an action profile in which for example one firm plays $C$ and all other firms play $M$ is also a Nash equilibrium. Nevertheless, the two important observations to make here are (1) that the action profile in which all firms play $C$, the collusion strategy profile, is not a Nash equilibrium, and (2) that in any symmetric Nash equilibrium (either all firms playing $M$ or all firms playing $U$ ) of the one shot game all firms receive zero profit.

The aim of the paper is to analyze the conditions under which collusion can be sustained as an equilibrium in the repeated version of this game, and thus to have positive profits for all firms in equilibrium.

\subsection{The repeated game}

In the repeated game the one shot game is played repeatedly, once in each period of time $t=0,1,2, \ldots$ At the start of period $t$ the vector $\varphi_{t}=\left(\varphi_{1 t}, \ldots, \varphi_{n t}\right)$ of market shares is determined. This vector is now stochastic, and it might in general depend on both the actions taken previously by the firms and on the realizations of market shares in earlier periods. Nevertheless, for simplicity we only study exogenous processes where the realizations do not depend on the actions taken by the firms.

Next, when $\varphi_{t}$ is realized, each firm receives information $h_{i t}$. Typically $h_{i t}$ is a record of all actions taken by firms in earlier periods, the realized market shares of all firms in earlier periods, and either a firm's own market share in the current period (private information), or all realized 
market shares in the current period (public information).

Thus, a strategy for firm $i$ in the repeated game is a function $s_{i}$ that prescribes for each time period $t$ the action $s_{i}\left(h_{i t}\right) \in\{U, C, M\}$ that firm $i$ chooses given the information $h_{i t}$. We require that $s_{i}\left(h_{i t}\right)$ be specified for any conceivable history $h_{i t}$, not just for those that are actually realized by previous actions of the firms. This is standard practice in game theoretic models and functions to facilitate the definition of (subgame perfect) Nash equilibrium. A firm should not only specify what it will do when all firms act according to agreement, but also how it will react to conceivable deviations from the agreement (and by extension also to deviations from deviations from the agreement, etc).

We write $s\left(h_{t}\right)=\left(s_{1}\left(h_{1 t}\right), \ldots, s_{n}\left(h_{n t}\right)\right)$ for the profile of actions that is played at time $t$ given the information $h_{t}=\left(h_{1 t}, \ldots, h_{n t}\right)$. Let $s^{t}$ denote the map $h_{t} \mapsto s\left(h_{t}\right)$. Let the initial division of market shares be given by $\varphi_{0}=\left(\varphi_{10}, \ldots, \varphi_{n 0}\right)$. Let $h_{0}=\left(h_{10}, \ldots, h_{n 0}\right)$ be the associated information to the firms. Let the density function $f_{i t}\left(\varphi_{i t+1} \mid \varphi_{i t}\right)$ denote the density of the probability distribution of $\varphi_{i t+1}$ conditional on the event that at time $t$ the market share of firm $i$ is $\varphi_{i t}$. Let $\mathbb{E}\left(\Pi_{i}\left(s^{t}\right) \mid h_{i 0}\right)$ denote the expected value of the payoff to firm $i$ at time $t$, given the strategy profile $s$ and the initial information $h_{i 0}$ of firm $i$.

Given the profile $s=\left(s_{1}, \ldots, s_{n}\right)$ of strategies, firm $i$ evaluates the resulting stream

$$
\mathbb{E}\left(\Pi_{i}\left(s^{0}\right) \mid h_{i 0}\right), \mathbb{E}\left(\Pi_{i}\left(s^{1}\right) \mid h_{i 0}\right), \ldots
$$

of expected profits via the discounted criterion

$$
\Pi_{i}\left(s \mid h_{i 0}\right)=\sum_{t=0}^{\infty} \delta^{t} \cdot \mathbb{E}\left(\Pi_{i}\left(s^{t}\right) \mid h_{i 0}\right)
$$

Given a strategy profile $s$ and a strategy $c_{i}$ for firm $i$, let $\left(s, c_{i}\right)$ denote the strategy profile where all firms $j \neq i$ play according to the strategy $s_{j}$, while firm $i$ plays according to strategy $c_{i}$. A strategy profile $s$ is a Bayesian Nash equilibrium when for every firm $i$

$$
\Pi_{i}\left(s \mid h_{i 0}\right) \geq \Pi_{i}\left(\left(s, c_{i}\right) \mid h_{i 0}\right)
$$

holds for every strategy $c_{i}$ of firm $i$ and any initial information $h_{i 0}$.

Analogously, let $\mathbb{E}\left(\Pi_{i}\left(s^{t+k}\right) \mid h_{i t}\right)$ denote the expected value of the payoff to firm $i$ at time $t+k$, given the strategy profile $s$ and information $h_{i t}$ to firm $i$ at time $t$. Write

$$
\Pi_{i}\left(s \mid h_{i t}\right)=\sum_{k=0}^{\infty} \delta^{k} \cdot \mathbb{E}\left(\Pi_{i}\left(s^{t+k}\right) \mid h_{i t}\right)
$$


for the expected payoff to firm $i$ at information set $h_{i t}$. A Nash equilibrium $s$ is a perfect Bayesian Nash equilibrium when, at every information set $h_{i t}$,

$$
\Pi_{i}\left(s \mid h_{i t}\right) \geq \Pi_{i}\left(\left(s, c_{i}\right) \mid h_{i t}\right)
$$

holds for every strategy $c_{i}$ of firm $i$.

\section{The effects of market share fluctuations on the sustain- ability of collusion when information is private}

In this section we assume private information. Thus, for every $i$ and $t, h_{i t}$ consists of $\varphi_{i t}$ together with all realizations of market shares and all actions taken by firms from all previous rounds. We consider the case where collusion is sustained via trigger strategies.

TRIGGER STRATEGIES The trigger strategy $T_{i}$ of firm $i$ is defined by

$$
T_{i}\left(h_{i t}\right)= \begin{cases}C & \text { if all firms chose action } C \text { in all previous rounds according to } h_{i t} \\ M & \text { otherwise }\end{cases}
$$

and $T=\left(T_{i}\right)_{i \in N}$ denotes the profile of trigger strategies. We want to investigate under which conditions $T$ constitutes a perfect Bayesian Nash equilibrium.

Let $f_{i t+1}\left(\varphi_{i t+1} \mid \varphi_{i t}\right)$ denote the density function of the probability distribution of $\varphi_{i t+1}$ when at time $t$ the market share of firm $i$ is $\varphi_{i t}$. We assume that all realizations of market shares are within an interval $[\underline{\varphi}, \bar{\varphi}]$. Specifically, we assume that $f_{i t+1}\left(\varphi_{i t+1} \mid \varphi_{i t}\right)=0$ outside the interval $[\underline{\varphi}, \bar{\varphi}]$ and that $f_{i t+1}\left(\varphi_{i t+1} \mid \varphi_{i t}\right)>0$ on the interior of the interval $[\underline{\varphi}, \bar{\varphi}]$.

Further, in accordance with the intuition that a higher market share today increases one's chances to have a higher market share in the future, we assume for the collection of cumulative probability distributions

$$
F_{\varphi_{i t}}(\varphi)=\int_{0}^{\varphi} f_{i t+1}\left(\varphi_{i t+1} \mid \varphi_{i t}\right) d \varphi_{i t+1}
$$

that $\varphi_{i t} \leq \widetilde{\varphi}_{i t}$ implies $F_{\varphi_{i t}}(\varphi) \geq F_{\widetilde{\varphi}_{i t}}(\varphi)$ for every $\varphi$. In words, when $\varphi_{i t} \leq \widetilde{\varphi}_{i t}$, the probability distribution $F_{\widetilde{\varphi}_{i t}}$ of $\varphi_{i t+1}$ given $\widetilde{\varphi}_{i t}$ stochastically dominates the probability distribution $F_{\varphi_{i t}}$ of $\varphi_{i t+1}$ given $\varphi_{i t}$.

It is well known that stochastic dominance implies the following statement for monotone transformations of $\varphi_{i t+1}$.

Lemma 4.1 Let $g\left(\varphi_{i t+1}\right) \geq 0$ be (strictly) increasing in $\varphi_{i t+1}$. Then

$$
\mathbb{E}\left(g \mid \varphi_{i t}\right)=\int g\left(\varphi_{i t+1}\right) \cdot f_{i t+1}\left(\varphi_{i t+1} \mid \varphi_{i t}\right) d \varphi_{i t+1}
$$


is (strictly) increasing in $\varphi_{i t}$.

Now write

$$
\mathbb{E}\left(\varphi_{i t+1} \mid \varphi_{i t}\right)=\int \varphi_{i t+1} \cdot f_{i t+1}\left(\varphi_{i t+1} \mid \varphi_{i t}\right) d \varphi_{i t+1} .
$$

By the previous Lemma, $\mathbb{E}\left(\varphi_{i t+1} \mid \varphi_{i t}\right)$ is a strictly increasing function of $\varphi_{i t}$. Thus, iterating the same argument, also

$$
\mathbb{E}\left(\varphi_{i t+2} \mid \varphi_{i t}\right)=\mathbb{E}\left(\mathbb{E}\left(\varphi_{i t+2} \mid \varphi_{i t+1}\right) \mid \varphi_{i t}\right)
$$

is a strictly increasing function of $\varphi_{i t}$. This way we find the following result.

Theorem 4.2 For any $k \geq 1, \mathbb{E}\left(\varphi_{i t+k} \mid \varphi_{i t}\right)$ is increasing in $\varphi_{i t}$.

Remark. The above equation

$$
\mathbb{E}\left(\varphi_{i t+2} \mid \varphi_{i t}\right)=\mathbb{E}\left(\mathbb{E}\left(\varphi_{i t+2} \mid \varphi_{i t+1}\right) \mid \varphi_{i t}\right) .
$$

that we used to derive Lemma 4.2 is not a definition, it is in fact a result. In order to see why this result is true it is convenient to derive the above equation for a discrete process. Let $M_{1}, M_{2}$ and $M_{3}$ be three finite sets. Suppose we have transition probabilities $P\left(m_{2} \mid m_{1}\right)$ and $P\left(m_{3} \mid m_{2}\right)$. Then

$$
P\left(m_{3} \mid m_{1}\right)=\sum_{m_{2}} P\left(m_{2} \mid m_{1}\right) \cdot P\left(m_{3} \mid m_{2}\right) .
$$

So,

$$
\begin{aligned}
\mathbb{E}\left(m_{3} \mid m_{1}\right) & =\sum_{m_{3}} P\left(m_{3} \mid m_{1}\right) \cdot m_{3} \\
& =\sum_{m_{3}} \sum_{m_{2}} P\left(m_{2} \mid m_{1}\right) \cdot P\left(m_{3} \mid m_{2}\right) \cdot m_{3} \\
& =\sum_{m_{2}}\left[\sum_{m_{3}} m_{3} \cdot P\left(m_{3} \mid m_{2}\right)\right] \cdot P\left(m_{2} \mid m_{1}\right) \\
& =\sum_{m_{2}} \mathbb{E}\left(m_{3} \mid m_{2}\right) \cdot P\left(m_{2} \mid m_{1}\right) \\
& =\mathbb{E}\left(\mathbb{E}\left(m_{3} \mid m_{2}\right) \mid m_{1}\right) .
\end{aligned}
$$

The equation we used above to compute $\mathbb{E}\left(\varphi_{i t+2} \mid \varphi_{i t}\right)$ is the continuous variant of the same result. The formula for the continuous case can be shown using the Theorem of Radon-Nikodym and Tonelli's Theorem. For further information we refer to Davidson (1994).

Now we can derive the following necessary and sufficient condition for $T$ to be a perfect Bayesian Nash equilibrium. 
Theorem 4.3 The strategy profile $T$ is a perfect Bayesian Nash equilibrium precisely when

$$
\sum_{k=0}^{\infty} \delta^{k} \cdot \mathbb{E}\left(\varphi_{i t+k} \mid \varphi_{i t}\right) \geq 1
$$

holds for all firms $i$, at every time $t$, for any possible market share $\varphi_{i t} \in[\underline{\varphi}, \bar{\varphi}]$ at time $t$.

Proof. Due to the one deviation property (see e.g. Hendon et al. (1996)), the trigger strategy profile is a perfect Bayesian Nash equilibrium exactly when every firm $i$, at every time $t$, and at every information set $h_{i t}$ the trigger strategy renders at least the same expected payoff as an instantaneous deviation. Thus, consider firm $i$, at time $t$, having a market share $\varphi_{i t}$. Given that in the punishment phase firms make zero profit, the expected loss in this phase equals the discounted sum of expected market shares times $\Pi$

$$
\delta \cdot \mathbb{E}\left(\varphi_{i t+1} \mid \varphi_{i t}\right) \cdot \Pi+\delta^{2} \cdot \mathbb{E}\left(\varphi_{i t+2} \mid \varphi_{i t}\right) \cdot \Pi+\ldots=\sum_{k=1}^{\infty} \delta^{k} \cdot \mathbb{E}\left(\varphi_{i t+k} \mid \varphi_{i t}\right) \cdot \Pi
$$

As $\Pi$ is a constant, this is equal to $\Pi \cdot \sum_{k=1}^{\infty} \delta^{k} \cdot \mathbb{E}\left(\varphi_{i t+k} \mid \varphi_{i t}\right)$. The gain from deviation is equal to $\left(1-\varphi_{i t}\right) \cdot \Pi$. So the collusive strategy renders at least the same payoff when

$$
\sum_{k=1}^{\infty} \delta^{k} \cdot \mathbb{E}\left(\varphi_{i t+k} \mid \varphi_{i t}\right) \geq 1-\varphi_{i t}
$$

This concludes the proof.

As a direct consequence of this characterization of perfect Bayesian Nash equilibrium we find that the smaller a firm's market share can get, the higher the discount factor needs to be to ensure that the trigger strategy profile is an equilibrium in all possible market share realizations. Formally we can express this insight as follows.

Corollary 4.4 The strategy profile $T$ is a perfect Bayesian Nash equilibrium precisely when

$$
\sum_{k=0}^{\infty} \delta^{k} \cdot \mathbb{E}\left(\varphi_{i t+k} \mid \varphi_{i t}=\underline{\varphi}\right) \geq 1
$$

holds for every firm $i$ at every time $t$.

Proof. Due to Theorem 4.3 we know that $T$ is a perfect Bayesian Nash equilibrium precisely when

$$
\sum_{k=0}^{\infty} \delta^{k} \cdot \mathbb{E}\left(\varphi_{i t+k} \mid \varphi_{i t}\right) \geq 1
$$

holds for all firms $i$, at every time $t$, for any possible market share $\varphi_{i t} \in[\underline{\varphi}, \bar{\varphi}]$ at time $t$. However, by Theorem 4.2 we know that the left-hand side of the above inequality is increasing 
in $\varphi_{i t}$. Hence, the above inequality is satisfied for all $\varphi_{i t} \in[\varphi, \bar{\varphi}]$ precisely when it is satisfied for $\varphi_{i t}=\underline{\varphi}$.

A second consequence of Theorem 4.3 is that, when a firm's market share is a martingale ${ }^{1}$, the trigger strategy is a perfect Bayesian Nash equilibrium precisely when the discount factor exceeds 1 minus the minimum market share. Thus, when the minimum market share is relatively high, and hence uncertainty is relatively low, it is easy for the firms to sustain collusion.

Corollary 4.5 When the stochastic variables $\varphi_{i}$ form a martingale, the trigger strategy profile is a perfect Bayesian Nash equilibrium precisely when $\delta \geq 1-\underline{\varphi}$.

Proof. When the stochastic variables $\varphi_{i}$ form a martingale, we know that

$$
\mathbb{E}\left(\varphi_{i t+k} \mid \varphi_{i t}=\underline{\varphi}\right)=\underline{\varphi}
$$

for all $t$ and $k^{2}$. Thus, the equilibrium condition in Corollary 4.4 reduces to

$$
\sum_{k=0}^{\infty} \delta^{k} \cdot \underline{\varphi} \geq 1
$$

which can be rewritten to $\delta \geq 1-\underline{\varphi}$.

Corollary 4.6 If the trigger strategy profile is a perfect Bayesian Nash equilibrium, then $\delta \geq$ $\frac{n-1}{n}$. Thus, collusion becomes harder to sustain when the number of firms increases.

Proof. Let $\varphi_{t}=\left(\varphi_{1 t}, \ldots, \varphi_{n t}\right)$ be a realization of market shares at time $t$. Summing up the corresponding equilibrium conditions from Theorem 4.3 over all firms yields the inequality

$$
\sum_{k=0}^{\infty} \delta^{k} \cdot \sum_{i=1}^{n} \mathbb{E}\left(\varphi_{i t+k} \mid \varphi_{i t}\right) \geq n .
$$

However, notice that for any realization $\varphi_{t}=\left(\varphi_{1 t}, \ldots, \varphi_{n t}\right)$ and any $k$ necessarily

$$
\sum_{i=1}^{n} \mathbb{E}\left(\varphi_{i t+k} \mid \varphi_{i t}\right)=1
$$

Hence,

$$
\sum_{k=0}^{\infty} \delta^{k} \geq n
$$

which can be rewritten to $\delta \geq \frac{n-1}{n}$.

\footnotetext{
${ }^{1}$ For firm $i$, the stochastic process $\left(\varphi_{i t}\right)_{t=0}^{\infty}$ is a martingale when $\mathbb{E}\left(\varphi_{i t+k} \mid \varphi_{i t}\right)=\varphi_{i t}$ for every $t$ and $k$.

${ }^{2}$ For a martingale it even holds that $\varphi_{i t+1}=\underline{\varphi}$ with probability one when $\varphi_{i t}=\underline{\varphi}$.
} 
As a final observation in this section, consider the case in which all market shares are fixed and equal to $\frac{1}{n}$. By Corollary 4.5 we know that in this case for $\delta=\frac{n-1}{n}$ the strategy profile $T$ is a perfect Bayesian Nash equilibrium. However, by the Corollary 4.6 we need $\delta \geq \frac{n-1}{n}$ to sustain $T$ as a perfect Bayesian Nash equilibrium in any case. Thus the case in which all market shares are fixed and equal to $\frac{1}{n}$ is the most favorable setting to sustain collusion under under the above choice of trigger strategies.

\section{Collusive price cutting when a firm's market share is low and information is public}

When firms have public information on realized market shares, the incentives to deviate for a firm that has a low market share can be reduced by jointly choosing a lower collusive price. That way, a deviating firm still attracts the entire market but against a lower price.

We model this phenomenon by adding an action to the one shot game. Let $C^{*}$ denote an action that generates a lower collusive price when it is chosen by all firms, and let $\Pi^{*}<\Pi$ denote the resulting joint collusive payoff. The action space of the one shot game becomes $\left\{C, C^{*}, M, U\right\}$. Payoffs are as follows. In case no firm chooses $C^{*}$, payoffs are as before. When at least one firm chooses $M$, all payoffs are zero. When no firm chooses $M$, and precisely one firm chooses $U$, this firm gets $\Pi$ when all other firms chose $C$, otherwise this firm gets $\Pi^{*}$. All other firms receive zero payoff. When at least two firms choose $U$, all payoffs are zero. When at least one firm chooses $C^{*}$, and all other firms choose either $C$ or $C^{*}$, the total payoff is $\Pi^{*}$, and all firms share the total payoff according to market shares ${ }^{3}$.

ADAPTIVE TRIGGER STRATEGIES Let $\varphi^{*} \geq \underline{\varphi}$ be a fixed market share level. We say that firm $i$ plays according to plan in round $t$ when either $\varphi_{j t} \geq \varphi^{*}$ for all $j$ and firm $i$ plays $C$ in round $t$, or alternatively $\varphi_{j t}<\varphi^{*}$ for some $j$ and firm $i$ plays $C^{*}$ in round $t$.

The adaptive trigger strategy $T_{i}^{*}$ of firm $i$ is defined by

$$
T_{i}^{*}\left(h_{i t}\right)= \begin{cases}C & \begin{array}{l}
\text { if, according to } h_{i t}, \text { all firms played according to plan } \\
\text { in all previous rounds, and } \varphi_{j t} \geq \varphi^{*} \text { for all } j
\end{array} \\
C^{*} \quad \begin{array}{l}
\text { if, according to } h_{i t}, \text { all firms played according to plan } \\
\text { in all previous rounds, and } \varphi_{j t}<\varphi^{*} \text { for some } j \\
M \quad \text { otherwise }
\end{array}\end{cases}
$$

\footnotetext{
${ }^{3}$ One might argue that in this case only firms that chose $C^{*}$ receive positive payoff. Our stance in this is though, that a collective decision to collude leads to collusion. Different choices of collusive price setting by different firms only drives the price down to the lower collusive price $C^{*}$ in a sequence of price reductions. However, because all firms chose to collude, this process of price reductions does not destroy collusive behavior. Thus, as we did before in the case where more than one firm chooses $U$, we decided to model the process of price reductions implicitly in the choice of payoffs for the firms.
} 
Note that firms need public information on market shares in order to execute this strategy. We write $T^{*}=\left(T_{i}^{*}\right)_{i \in N}$ for the profile of adaptive trigger strategies. We want to investigate under which conditions $T^{*}$ constitutes a (perfect) Bayesian Nash equilibrium. Let $p_{t+k}\left(h_{t}\right)$ be the probability that $\varphi_{j t+k} \geq \varphi^{*}$ for all $j$.

Theorem 5.1 The strategy profile $T^{*}$ is a perfect Bayesian Nash equilibrium precisely when for every firm $i$ and for every information set $h_{t}$ at every time $t$, the condition

$$
\sum_{k=1}^{\infty} \delta^{k} \cdot \mathbb{E}\left(\varphi_{i t+k} \mid \varphi_{i t}\right) \cdot\left(p_{t+k}\left(h_{t}\right) \Pi+\left(1-p_{t+k}\left(h_{t}\right)\right) \Pi^{*}\right) \geq\left(1-\varphi_{i t}\right) \Pi
$$

holds when $\varphi_{j t} \geq \varphi^{*}$ for all $j$, and the condition

$$
\sum_{k=1}^{\infty} \delta^{k} \cdot \mathbb{E}\left(\varphi_{i t+k} \mid \varphi_{i t}\right) \cdot\left(p_{t+k}\left(h_{t}\right) \Pi+\left(1-p_{t+k}\left(h_{t}\right)\right) \Pi^{*}\right) \geq\left(1-\varphi_{i t}\right) \Pi^{*}
$$

holds when $\varphi_{j t}<\varphi^{*}$ for some $j$.

Proof. The proof generally follows the same steps as the proofs of Theorem 4.3 and Corollary 4.4. Consider a firm $i$ at time $t$ with market share $\varphi_{i t}$. If the firm would play $U$, the expected loss from the punishment period would be

$$
\sum_{k=1}^{\infty} \delta^{k} \cdot \mathbb{E}\left(\varphi_{i t+k} \mid \varphi_{i t}\right) \cdot\left(p_{t+k}\left(h_{t}\right) \Pi+\left(1-p_{t+k}\left(h_{t}\right)\right) \Pi^{*}\right) .
$$

The expected gain when $\varphi_{j t} \geq \varphi^{*}$ for all $j$ is $\left(1-\varphi_{i t}\right) \Pi$. So, in this case the equilibrium condition becomes

$$
\sum_{k=1}^{\infty} \delta^{k} \cdot \mathbb{E}\left(\varphi_{i t+k} \mid \varphi_{i t}\right) \cdot\left(p_{t+k}\left(h_{t}\right) \Pi+\left(1-p_{t+k}\left(h_{t}\right)\right) \Pi^{*}\right) \geq\left(1-\varphi_{i t}\right) \Pi .
$$

When $\varphi_{j t}<\varphi^{*}$ for some $j$ the expected gain is $\left(1-\varphi_{i t}\right) \Pi^{*}$. So, in this case the equilibrium condition becomes

$$
\sum_{k=1}^{\infty} \delta^{k} \cdot \mathbb{E}\left(\varphi_{i t+k} \mid \varphi_{i t}\right) \cdot\left(p_{t+k}\left(h_{t}\right) \Pi+\left(1-p_{t+k}\left(h_{t}\right)\right) \Pi^{*}\right) \geq\left(1-\varphi_{i t}\right) \Pi^{*}
$$

The next corollary shows that there is indeed an appropriate choice of $\varphi^{*}$ that guarantees that an equilibrium in adaptive trigger strategies requires a lower $\delta$ than an equilibrium in trigger strategies.

Corollary 5.2 Suppose that the stochastic variables $\varphi_{i}$ form a martingale. Let $\delta$ be given. Suppose further that

$$
\varphi^{*} \geq \frac{(1-\delta) \Pi}{\delta \Pi^{*}+(1-\delta) \Pi}
$$


Then the adaptive trigger strategy profile $T^{*}$ is a perfect Bayesian Nash equilibrium given $\delta$ whenever the trigger strategy profile $T$ is a perfect Bayesian Nash equilibrium given $\delta$.

Proof. Suppose that

$$
\varphi^{*} \geq \frac{(1-\delta) \Pi}{\delta \Pi^{*}+(1-\delta) \Pi}
$$

Rewriting yields

$$
\sum_{k=1}^{\infty} \delta^{k} \cdot \varphi^{*} \cdot \Pi^{*} \geq\left(1-\varphi^{*}\right) \Pi
$$

Since the left-hand side of the inequality is increasing in $\varphi^{*}$ and the left-hand side in decreasing, we obtain

$$
\sum_{k=1}^{\infty} \delta^{k} \cdot \varphi_{i t} \cdot \Pi^{*} \geq\left(1-\varphi_{i t}\right) \Pi
$$

for all $\varphi_{i t} \geq \varphi^{*}$. Thus, since the stochastic variables $\varphi_{i}$ form a martingale, we find that

$$
\sum_{k=1}^{\infty} \delta^{k} \cdot \mathbb{E}\left(\varphi_{i t+k} \mid \varphi_{i t}\right) \cdot \Pi^{*} \geq\left(1-\varphi_{i t}\right) \Pi
$$

for all $\varphi_{i t} \geq \varphi^{*}$. Hence, since $\Pi^{*}<\Pi$, also

$$
\sum_{k=1}^{\infty} \delta^{k} \cdot \mathbb{E}\left(\varphi_{i t+k} \mid \varphi_{i t}\right) \cdot\left(p_{t+k}\left(h_{t}\right) \Pi+\left(1-p_{t+k}\left(h_{t}\right)\right) \Pi^{*}\right) \geq\left(1-\varphi_{i t}\right) \Pi
$$

for all $\varphi_{i t} \geq \varphi^{*}$, which shows that the first set of inequalities of Theorem 5.1 is satisfied. In order to obtain the second set of inequalities, notice that he strategy profile $T$ is a perfect Bayesian Nash equilibrium by assumption. So, by Theorem 4.3

$$
\sum_{k=0}^{\infty} \delta^{k} \cdot \mathbb{E}\left(\varphi_{i t+k} \mid \varphi_{i t}\right) \geq 1
$$

for all $t$ and all market shares $\varphi_{i t}$. Therefore also

$$
\sum_{k=1}^{\infty} \delta^{k} \cdot \mathbb{E}\left(\varphi_{i t+k} \mid \varphi_{i t}\right) \cdot \Pi^{*} \geq\left(1-\varphi_{i t}\right) \Pi^{*}
$$

for all $t$ and all market shares $\varphi_{i t}$. The second set of conditions now follows from the observation that $\Pi^{*}<\Pi$.

Finally note that the condition $\varphi^{*} \geq \frac{(1-\delta) \Pi}{\delta \Pi^{*}+(1-\delta) \Pi}$ can be satisfied for any given $\delta<1$ by an appropriate choice of $\varphi^{*}<1$. A minimum condition to have fully collusive behavior as a possibility under the adaptive trigger strategies is $\frac{1}{n} \geq \frac{(1-\delta) \Pi}{\delta \Pi^{*}+(1-\delta) \Pi}$. This inequality can be rewritten to $\frac{(n-1) \Pi}{(n-1) \Pi+\Pi^{*}} \leq \delta$. 


\section{Semi-collusive equilibria}

We now turn our attention to other types of equilibrium strategies in our model. In the context of full and private information on market shares, we look at equilibria in which firms play collusively as long as all market shares exceed a certain threshold. In the next analysis, the chance mechanism $\varphi$ that generates the market share fluctuation is of the following form: $\varphi_{t}=$ $\left(\varphi_{1 t}, \varphi_{2 t}, \cdots, \varphi_{n t}\right)$ is drawn from a uniform and i.i.d. distribution. This implies that tomorrow's market share division is independent of today's. We further assume that $[\underline{\varphi}, \bar{\varphi}]=[0,1]$.

\subsection{Public information}

In this subsection, we analyze the case in which firms learn the entire realization of $\varphi_{t}$ at the beginning of period $t$. That is, $\varphi_{t}$ is included in $h_{i t}$ for all $i$ and $t$. We consider the case where temporary collusion is sustained via so-called threshold trigger strategies.

THRESHOLD TRIGGER STRATEGIES (WITH PUBLIC INFORMATION) Let $\widetilde{\varphi} \in\left[0, \frac{1}{n}\right]$ be given (in advance chosen by the firms). The threshold trigger strategy $T P U_{i}$ of firm $i$ with threshold $\widetilde{\varphi}$ is defined by

$$
T P U_{i}\left(h_{i t}\right)= \begin{cases}C & \text { if all firms chose action } C \text { in all previous rounds according to } h_{i t} \\ \text { and } \varphi_{j t} \geq \widetilde{\varphi} \text { for all } j \in N & \text { otherwise }\end{cases}
$$

We write $T P U=\left(T P U_{i}\right)_{i \in N}$ for the profile of threshold trigger strategies with full information. We want to investigate under which conditions $T P U$ constitutes a perfect Bayesian Nash equilibrium.

Lemma 6.1 Let the market share distribution $\varphi_{t}$ with $\varphi_{i t} \geq 0$ and $\sum_{i} \varphi_{i t}=1$ be drawn from a uniform distribution. Then, the probability that all firms have at least a market share of $\widetilde{\varphi} \leq \frac{1}{n}$ is equal to

$$
\mathbb{P}\left[\varphi_{i t} \geq \widetilde{\varphi}, \forall i \in N\right]=(1-n \widetilde{\varphi})^{n-1}
$$

Proof. Consider a standard $(n-1)$-dimensional simplex with vertices

$$
(1,0, \ldots, 0) ;(0,1, \ldots, 0) ; \ldots ;(0,0, \ldots, 1)
$$

This simplex represents all possible market share realizations. The barycenter of this simplex is $\left(\frac{1}{n}, \frac{1}{n}, \ldots, \frac{1}{n}\right)$. The distance from the barycenter to a vertex equals

$$
\sqrt{(n-1)\left(\frac{1}{n}\right)^{2}+\left(\frac{1-n}{n}\right)^{2}}=\sqrt{\frac{n-1}{n}} .
$$


Now consider the $(n-1)$-dimensional simplex with vertices

$$
(1-(n-1) \widetilde{\varphi}, \widetilde{\varphi}, \ldots, \widetilde{\varphi}) ;(\widetilde{\varphi}, 1-(n-1) \widetilde{\varphi}, \ldots, \widetilde{\varphi}) ; \ldots ;(\widetilde{\varphi}, \widetilde{\varphi}, \ldots, 1-(n-1) \widetilde{\varphi})
$$

This simplex represents all possible market share realizations in which each firm has at least a market share of $\widetilde{\varphi}$ and has the barycenter at $\left(\frac{1}{n}, \frac{1}{n}, \ldots, \frac{1}{n}\right)$ as well. The distance from the barycenter to a vertex of this simplex is

$$
\sqrt{(n-1)\left(\frac{1}{n}-\widetilde{\varphi}\right)^{2}+\left(\frac{1}{n}-(1-(n-1) \widetilde{\varphi})\right)^{2}}=(1-n \widetilde{\varphi}) \sqrt{\frac{n-1}{n}} .
$$

As the simplex has $(n-1)$ dimensions, the volume of the second simplex is $(1-n \widetilde{\varphi})^{n-1}$ times the volume of the first one.

Theorem 6.2 The strategy profile TPU is a perfect Bayesian Nash equilibrium precisely when

$$
\widetilde{\varphi}+\frac{\delta(1-n \widetilde{\varphi})^{n-1}}{1-\delta(1-n \widetilde{\varphi})^{n-1}} \cdot \frac{1}{n} \geq 1 .
$$

Proof. Let $\Phi$ denote the set of market share realizations with $\varphi_{i} \geq \widetilde{\varphi}$ for all firms $i \in N$. Due to the one deviation property, the trigger strategy profile is a perfect Bayesian Nash equilibrium exactly when every firm $i$, at every time $t$, and at every information set $h_{i t}$ the trigger strategy renders at least the same expected payoff as an instantaneous deviation. Thus, consider firm $i$, at time $t$, at information set $h_{i t}$. Let $\mathbb{E}\left[T P U \mid h_{i t}\right]$ denote the expected payoff of following the threshold trigger strategy, and $\mathbb{E}\left[D \mid h_{i t}\right]$ the expected payoff of an instantaneous optimal deviation, both given market share vector $\varphi_{t}$ and given that the opponents play according to $T P U$. We need to analyze two separate situations.

A. When $\varphi_{t} \notin \Phi$. Given that the opponents play $M$ forever according to $T P U$, firm $i$ will get an expected payoff of 0 , no matter what its strategy is. The equilibrium condition

$$
\mathbb{E}\left[T P U \mid h_{i t}\right] \geq \mathbb{E}\left[D \mid h_{i t}\right]
$$

is therefore trivially satisfied in this case.

B. When $\varphi_{t} \in \Phi$. Deviation from $T P U$ will render a one-period monopoly payoff after which profits will be equal to 0 . Therefore $\mathbb{E}\left[D \mid \varphi_{t} \in \Phi\right]=\Pi$. On the other hand the expected payoff of following $T P U$ is equal to

$$
\begin{aligned}
\mathbb{E}\left[T P U \mid \varphi_{t} \in \Phi\right]=\varphi_{i t} \Pi+ & \delta \mathbb{P}\left[\varphi_{t+1} \notin \Phi\right] \cdot \mathbb{E}\left[T P U \mid \varphi_{t+1} \notin \Phi\right] \\
& +\delta \mathbb{P}\left[\varphi_{t+1} \in \Phi\right] \cdot \mathbb{E}\left[T P U \mid \varphi_{t+1} \in \Phi\right] .
\end{aligned}
$$


According to Lemma $6.1, \mathbb{P}\left[\varphi_{t+1} \in \Phi\right]=(1-n \widetilde{\varphi})^{n-1}$. Furthermore, $\mathbb{E}\left[T P U \mid \varphi_{t+1} \notin \Phi\right]=$ 0 . Since the expectation of future market shares and payoff is independent from the current situation, $\left.\mathbb{E}\left[T P U \mid \varphi_{t+k} \in \Phi\right]\right)$ is constant for any $k \geq 1$ and equal to

$$
\frac{1}{n} \cdot \frac{\Pi}{1-\delta(1-n \widetilde{\varphi})^{n-1}}
$$

Substitution and rewriting yields

$$
\mathbb{E}\left[T P U \mid \varphi_{t} \in \Phi\right]=\left(\varphi_{i t}+\frac{\delta(1-n \widetilde{\varphi})^{n-1}}{1-\delta(1-n \widetilde{\varphi})^{n-1}} \cdot \frac{1}{n}\right) \Pi .
$$

The equilibrium condition $\mathbb{E}\left[T P U \mid \varphi_{t} \in \Phi\right] \geq \mathbb{E}\left[D \mid \varphi_{t} \in \Phi\right]$ is thus satisfied when

$$
\left(\varphi_{i t}+\frac{\delta(1-n \widetilde{\varphi})^{n-1}}{1-\delta(1-n \widetilde{\varphi})^{n-1}} \cdot \frac{1}{n}\right) \geq 1 .
$$

Finally notice that the left-hand side of the above inequality is increasing in $\varphi_{i t}$. Since the condition should hold for all possible $\varphi_{i t}$ with $\varphi_{t} \in \Phi$, it suffices to require that the inequality holds for $\varphi_{i t}=\widetilde{\varphi}$.

Corollary 6.3 Permanent collusive behavior in the threshold trigger strategy profile with public information requires a higher discount factor than permanent collusive behavior when demand fluctuations are impossible and demand is equally divided.

Proof. In a model without demand fluctuation and with equal demand division, firms will not deviate from the trigger strategy profile when $\frac{1}{1-\delta} \frac{1}{n} \Pi \geq \Pi$. This is equivalent to $\delta \geq \frac{n-1}{n}$. If $\widetilde{\varphi}=0$, the equilibrium condition in Theorem 6.2 becomes $\frac{\delta}{n-n \delta} \geq 1$. This is equivalent to $\delta \geq \frac{n}{n+1}$.

The following corollary states for which discount factors there exists a strategy profile $T P U$ that forms a perfect Bayesian Nash equilibrium.

Corollary 6.4 When $\delta<\frac{n}{n+1}$, there exists no $\widetilde{\varphi} \leq \frac{1}{n}$ for which the strategy profile TPU forms a perfect Bayesian Nash equilibrium. When $\delta=\frac{n}{n+1}$, TPU forms a perfect Bayesian Nash equilibrium precisely when $\widetilde{\varphi}=0$. When $\delta>\frac{n}{n+1}$, there exists a $\varphi^{*} \in\left[0, \frac{1}{n}\right]$ such that TPU forms a perfect Bayesian Nash equilibrium precisely when $\widetilde{\varphi} \in\left[0, \varphi^{*}\right]$.

Proof. Consider the function

$$
f(\varphi)=1-\frac{\delta(1-n \varphi)^{n-1}}{1-\delta(1-n \varphi)^{n-1}} \cdot \frac{1}{n}
$$

on the domain $\left[0, \frac{1}{n}\right]$. From Theorem 6.2 we know that $T P U$ is an equilibrium precisely when $\widetilde{\varphi} \geq f(\widetilde{\varphi})$. We check when this condition is satisfied. 
Since $f$ is strictly increasing and concave on its domain, and since $f\left(\frac{1}{n}\right)>\frac{1}{n}$, we know that, if $f(\widetilde{\varphi}) \geq \widetilde{\varphi}$, then $f(\varphi)>\varphi$ for all $\varphi \in\left(\widetilde{\varphi}, \frac{1}{n}\right]$. Thus, the set of $\varphi$ with $\varphi \geq f(\varphi)$ is of the form $\left[0, \varphi^{*}\right]$ (possibly empty) for some $\varphi^{*}$.

When $\delta<\frac{n}{n+1}$. Then $f(0)>0$. Thus there are no $\varphi$ with $\varphi \geq f(\varphi)$.

When $\delta=\frac{n}{n+1}$. Then $f(0)=0$, and $\varphi \geq f(\varphi)$ only holds for $\varphi=0$.

When $\delta>\frac{n}{n+1}, f(0)<0$. Then by the Theorem of Brouwer there exists a point $\varphi^{*}$ with $f\left(\varphi^{*}\right)=\varphi^{*}$. By the argument we gave above this point $\varphi^{*}$ is unique, and the set $\left[0, \varphi^{*}\right]$ is exactly the set of solutions $\varphi$ of the inequality $\varphi \geq f(\varphi)$.

Remark. The equilibrium in which $\widetilde{\varphi}=0$ is Pareto-optimal among the possible equilibria in threshold trigger strategies with full information. However, also higher choices for the threshold $\widetilde{\varphi}$ are sustainable in equilibrium. Nevertheless, in such equilibria, with probability 1 firms switch to marginal cost pricing (playing $M$ ) at some moment in time. This feature makes these strategies harder to recognize as being collusive.

\subsection{Private Information}

In this subsection, we analyze the case in which firms learn only their own market share $\varphi_{i t}$ at the beginning of period $t$. I.e. $\varphi_{i t}$ is part of $h_{i t}$ for all $i \in N$, but $\varphi_{t}$ is not. Threshold trigger strategies in this setting are defined as follows.

THRESHOLd TRIGGER STRATEGIES (With PRIVATE INFORMATION) We assume $n \geq 3{ }^{4}$. Again, let the threshold $\widetilde{\varphi} \leq \frac{1}{n}$ be chosen in advance by the firms. The threshold trigger strategy $T P R_{i}$ of firm $i$ is defined by

$\operatorname{TPR}_{i}\left(h_{i t}\right)= \begin{cases}C & \text { if all firms chose } C \text { in all previous rounds according to } h_{i t}, \text { and } \varphi_{i t} \geq \widetilde{\varphi} \\ U & \text { if all firms chose } C \text { in all previous rounds according to } h_{i t}, \text { and } \varphi_{i t}<\widetilde{\varphi} \\ M & \text { otherwise }\end{cases}$

We write $T P R=\left(T P R_{i}\right)_{i \in N}$ for the profile of threshold trigger strategies with private information. We want to investigate under which conditions $T P R$ constitutes a perfect Bayesian Nash equilibrium.

We use the following notation. Let $\widehat{\varphi}=1-(n-1) \widetilde{\varphi}$. Further, write $P_{i t}$ for the probability that $\varphi_{j t} \geq \widetilde{\varphi}$ for all $j \neq i$ given $\varphi_{i t}$. Note that, when $\varphi_{i t}>\widehat{\varphi}$, we have at least one firm $j \neq i$ with $\varphi_{j t}<\widetilde{\varphi}$. Hence, $P_{i t}=0$ in that case.

\footnotetext{
${ }^{4}$ Note that, when $n=2$, we have $\varphi_{1 t}+\varphi_{2 t}=1$ for all $t$, so that private information regarding own market share is equivalent to public information. This case is treated in the previous subsection.
} 
Lemma 6.5 Let the market share distribution $\varphi_{t}$ be drawn from the uniform distribution. Suppose that $\varphi_{i t} \leq \widehat{\varphi}$. Then, given $\varphi_{i t}$,

$$
P_{i t}=\left(1-\frac{(n-1) \widetilde{\varphi}}{1-\varphi_{i t}}\right)^{n-2} .
$$

Proof. Consider an $(n-1)$-dimensional simplex with vertices

$$
\left(\varphi_{i t}, 1-\varphi_{i t}, 0, \ldots, 0\right) ;\left(\varphi_{i t}, 0,1-\varphi_{i t}, \ldots, 0\right) ; \ldots ;\left(\varphi_{i t}, 0,0, \ldots, 1-\varphi_{i t}\right) .
$$

This simplex represents all possible market share realizations in which the first firm has a market share of $\varphi_{i t}$. The barycenter of this simplex is $\left(\varphi_{i t}, \frac{1-\varphi_{i t}}{n-1}, \ldots, \frac{1-\varphi_{i t}}{n-1}\right)$. The distance from the barycenter to a vertex is

$$
\sqrt{(n-2)\left(\frac{1-\varphi_{i t}}{n-1}\right)^{2}+\left(\frac{1-\varphi_{i t}}{n-1}-\left(1-\varphi_{i t}\right)\right)^{2}}=\sqrt{\frac{(n-2)\left(\varphi_{i t}-1\right)^{2}}{n-1}} .
$$

Now consider the $(n-1)$-dimensional simplex with vertices

$$
\left(\varphi_{i t}, 1-\varphi_{i t}-(n-2) \widetilde{\varphi}, \widetilde{\varphi}, \ldots, \widetilde{\varphi}\right) ; \ldots \ldots ;\left(\varphi_{i t}, \widetilde{\varphi}, \widetilde{\varphi}, \ldots, 1-\varphi_{i t}-(n-2) \widetilde{\varphi}\right)
$$

This simplex represents all possible market share realizations in which the first firm has market share $\varphi_{i t}$ and all other firms have at least a market share of $\widetilde{\varphi}$. The barycenter of this simplex is also at $\left(\varphi_{i t}, \frac{1-\varphi_{i t}}{n-1}, \ldots, \frac{1-\varphi_{i t}}{n-1}\right)$. Straightforward calculation shows that the distance from the barycenter to a vertex of this simplex is

$$
\left(1-\frac{(n-1) \widetilde{\varphi}}{1-\varphi_{i t}}\right) \sqrt{\frac{(n-2)\left(\varphi_{i t}-1\right)^{2}}{n-1}} .
$$

As the simplices differ in $(n-2)$ dimensions, the volume of the second simplex is $\left(1-\frac{(n-1) \widetilde{\varphi}}{1-\varphi_{i t}}\right)^{n-2}$ times the volume of the first one.

Lemma 6.6 Let the market share distribution $\varphi_{t}$ be drawn from a uniform distribution with $\varphi_{i t} \geq 0$ and $\sum_{i} \varphi_{i t}=1$. Then, the cumulative distribution function of $\varphi_{i t}$ is

$$
F\left(\varphi_{i t}\right)=1-\left(1-\varphi_{i t}\right)^{n-1}
$$

Proof. Consider the standard $(n-1)$-dimensional simplex with vertices

$$
(1,0, \ldots, 0) ;(0,1, \ldots, 0) ; \ldots ;(0,0, \ldots, 1)
$$

If we intersect this simplex by the halfspace $\varphi_{i} \geq \varphi^{*}$ we get a smaller simplex of dimension $(n-1)$. Multiplication by a factor of $\frac{1}{1-\varphi^{*}}$ using the $i^{\text {th }}$ unit vector as the origin transforms the 
smaller simplex into the larger one. Thus, because these simplices have $(n-1)$ dimensions, the volume of the second simplex is $\left(1-\varphi^{*}\right)^{n-1}$ times the first one. Hence, since the value $F\left(\varphi^{*}\right)$ of the cumulative distribution function evaluated at $\varphi_{i}=\varphi^{*}$ equals 1 minus the probability of the smaller simplex, we find that $F\left(\varphi_{i}\right)=1-\left(1-\varphi_{i t}\right)^{n-1}$.

Theorem 6.7 If $\widetilde{\varphi}>0$, the strategy profile $T P R$ is a perfect Bayesian Nash equilibrium precisely when

$$
\widetilde{\varphi}+\delta \cdot \frac{n \cdot(1-(n-1) \widetilde{\varphi})^{n-1}-(n-1) \cdot(1-n \widetilde{\varphi})^{n-1}}{n \cdot\left(1-\delta \cdot(1-n \widetilde{\varphi})^{n-1}\right)}=1
$$

If $\widetilde{\varphi}=0, T P R$ is a perfect Bayesian Nash equilibrium precisely when $\delta \geq \frac{n}{n+1}$.

Proof. Due to the one deviation property, the trigger strategy profile is a perfect Bayesian Nash equilibrium exactly when every firm $i$, at every time $t$, and at every information set $h_{i t}$ the trigger strategy renders at least the same expected payoff as an instantaneous deviation. Thus, consider firm $i$, at time $t$, having a market share $\varphi_{i t}$. Let $\mathbb{E}\left[T P R \mid \varphi_{i t}\right]$ denote the expected payoff of following the threshold trigger strategy, and $\mathbb{E}\left[D \mid \varphi_{i t}\right]$ the expected payoff of an instantaneous optimal deviation, both given information set $h_{i t}$ and given that the opponents play according to $T P R$. We analyze three separate situations.

A. If $\varphi_{i t}>\widehat{\varphi}$. In this case, according to $T P R$, there will be at least one opponent playing $U$ in the next period, after which $M$ will be played forever. Thus, firm $i$ will get an expected payoff of 0 , no matter what its strategy is. Hence in this case, $\mathbb{E}\left[T P R \mid \varphi_{i t}\right]=0=\mathbb{E}\left[D \mid \varphi_{i t}\right]$, and the equilibrium condition $\mathbb{E}\left[T P R \mid \varphi_{i t}\right] \geq \mathbb{E}\left[D \mid \varphi_{i t}\right]$ is trivially satisfied.

The other two cases require more attention. We start with deriving expressions for both expected payoffs $\mathbb{E}\left[D \mid \varphi_{i t}\right]$ and $\mathbb{E}\left[T P R \mid \varphi_{i t}\right]$ for the other two cases.

B. If $\widetilde{\varphi} \leq \varphi_{i t} \leq \widehat{\varphi}$. In this situation, deviation from $T P R$ will render a one-period payoff of $\Pi$, provided there is no firm with a market share less than $\widetilde{\varphi}$, after which the firm will receive a payoff of 0 infinitely. Thus we find that

$$
\mathbb{E}\left[D \mid \varphi_{i t}\right]=P_{i t} \cdot \Pi
$$

Following $T P R$ yields an expected payoff $\mathbb{E}\left[T P R \mid \varphi_{i t}\right]$ equal to

$$
\begin{aligned}
P_{i t} \cdot \varphi_{i t} \cdot \Pi & +\delta \cdot P_{i t} \cdot \mathbb{P}\left[\varphi_{i t+1}<\widetilde{\varphi}\right] \cdot \mathbb{E}\left[T P R \mid \varphi_{i t+1}<\widetilde{\varphi}\right] \\
& +\delta \cdot P_{i t} \cdot \mathbb{P}\left[\widetilde{\varphi} \leq \varphi_{i t+1} \leq \widehat{\varphi}\right] \cdot \mathbb{E}\left[T P R \mid \widetilde{\varphi} \leq \varphi_{i t+1} \leq \widehat{\varphi}\right]
\end{aligned}
$$

Now notice that this can be rewritten to

$$
\mathbb{E}\left[T P R \mid \varphi_{i t}\right]=P_{i t} \cdot\left(\varphi_{i t} \cdot \Pi+Q\right)
$$


where

$$
Q=\delta \cdot \mathbb{P}\left[\varphi_{i t+1}<\widetilde{\varphi}\right] \cdot \mathbb{E}\left[T P R \mid \varphi_{i t+1}<\widetilde{\varphi}\right]+\delta \cdot \mathbb{P}\left[\widetilde{\varphi} \leq \varphi_{i t+1} \leq \widehat{\varphi}\right] \cdot \mathbb{E}\left[T P R \mid \widetilde{\varphi} \leq \varphi_{i t+1} \leq \widehat{\varphi}\right]
$$

C. If $\varphi_{i t}<\widetilde{\varphi}$. The optimal deviation from $T P R$ in this case is playing $C$. Playing $C$ ensures continuation of collusion, provided no other firm plays $U$ in the next period. Therefore, using the same reasoning as above, we find that in this case

$$
\mathbb{E}\left[D \mid \varphi_{i t}\right]=P_{i t} \cdot\left(\varphi_{i t} \cdot \Pi+Q\right)
$$

Following $T P R$ in this case, and thereby attracting the entire market for one period unless there is also another deviator, yields, as it does for $\mathbb{E}\left[D \mid \varphi_{i t}\right]$ in case $\mathrm{A}$,

$$
\mathbb{E}\left[T P R \mid \varphi_{i t}\right]=P_{i t} \cdot \Pi .
$$

We have derived expressions for $\mathbb{E}\left[D \mid \varphi_{i t}\right]$ and $\mathbb{E}\left[T P R \mid \varphi_{i t}\right]$ for both cases. Notice that the expression $P_{i t} \cdot \Pi$ equals both $\mathbb{E}\left[D \mid \varphi_{i t}\right]$ in case $\mathrm{B}$ and $\mathbb{E}\left[T P R \mid \varphi_{i t}\right]$ in case $\mathrm{C}$. The expression $P_{i t} \cdot\left(\varphi_{i t} \cdot \Pi+Q\right)$ equals both $\mathbb{E}\left[D \mid \varphi_{i t}\right]$ in case $\mathrm{C}$ and $\mathbb{E}\left[T P R \mid \varphi_{i t}\right]$. Moreover, $\Pi$ is a constant, while $\varphi_{i t} \cdot \Pi+Q$ is linearly increasing in $\varphi_{i t}$. Therefore, since $P_{i t}$ is non-negative and continuous in $\varphi_{i t}$, we can deduce that the equilibrium condition

$$
\mathbb{E}\left[T P R \mid \varphi_{i t}\right] \geq \mathbb{E}\left[D \mid \varphi_{i t}\right] \quad \text { for all } \varphi_{i t}
$$

is equivalent to the requirement that

$$
\mathbb{E}\left[T P R \mid \varphi_{i t}=\widetilde{\varphi}\right]=\mathbb{E}\left[D \mid \varphi_{i t}=\widetilde{\varphi}\right]
$$

This equality boils down to the equation

$$
\widetilde{\varphi} \cdot \Pi+Q=\Pi
$$

We compute $Q$ as follows. Write $V=\mathbb{E}\left[T P R \mid \widetilde{\varphi} \leq \varphi_{i t} \leq \widehat{\varphi}\right]$ and $P_{1}=\mathbb{P}\left[\widetilde{\varphi} \leq \varphi_{i t+1} \leq \hat{\varphi}\right]$. Then, using the fact that $\widehat{\varphi}=1-(n-1) \widetilde{\varphi}$,

$$
P_{1} \cdot V=\int_{\widetilde{\varphi}}^{1-(n-1) \widetilde{\varphi}} \mathbb{E}\left[T P R \mid \varphi_{i t}\right] \cdot F^{\prime}\left(\varphi_{i t}\right) d \varphi_{i t},
$$

where $\mathbb{E}\left[T P R \mid \varphi_{i t}\right]$ is given by the expression in case $\mathrm{B}$, and

$$
F^{\prime}\left(\varphi_{i t}\right)=(n-1) \cdot\left(1-\varphi_{i t}\right)^{n-2}
$$

is the density of the cumulative probability distribution in Lemma 6.6. Using the formula from Lemma 6.5 for $P_{i t}$ we find that the integrand is

$$
\mathbb{E}\left[T P R \mid \varphi_{i t}\right] \cdot F^{\prime}\left(\varphi_{i t}\right)=(n-1) \cdot\left(1-(n-1) \widetilde{\varphi}-\varphi_{i t}\right)^{n-2} \cdot\left(\varphi_{i t} \cdot \Pi+Q\right) .
$$


Thus, computing the integral, we find that

$$
P_{1} \cdot V=(1-n \widetilde{\varphi})^{n-1} \cdot\left(\frac{\Pi}{n}+Q\right) .
$$

We compute $Q$, using its definition in B. To do so, write $P_{2}=\mathbb{P}\left[\varphi_{i t+1}<\widetilde{\varphi}\right]$. Further, since $V$ does not depend on time, we can also write $V=\mathbb{E}\left[T P R \mid \widetilde{\varphi} \leq \varphi_{i t+1} \leq \hat{\varphi}\right]$. Using this notation, we have

$$
Q=\delta \cdot P_{2} \cdot \mathbb{E}\left[T P R \mid \varphi_{i t+1}<\widetilde{\varphi}\right]+\delta \cdot P_{1} \cdot V .
$$

Combining this with the above expression for $P_{1} \cdot V$ we find that

$$
Q=\delta \cdot P_{2} \cdot \mathbb{E}\left[T P R \mid \varphi_{i t+1}<\widetilde{\varphi}\right]+\delta \cdot(1-n \widetilde{\varphi})^{n-1} \cdot\left(\frac{\Pi}{n}+Q\right) .
$$

Solving for $Q$ yields

$$
\left(1-\delta \cdot(1-n \widetilde{\varphi})^{n-1}\right) \cdot Q=\frac{\delta \cdot(1-n \widetilde{\varphi})^{n-1} \cdot \Pi}{n}+\delta \cdot P_{2} \cdot \mathbb{E}\left[T P R \mid \varphi_{i t+1}<\widetilde{\varphi}\right] .
$$

Thus,

$$
Q=\delta \cdot \frac{(1-n \widetilde{\varphi})^{n-1} \cdot \Pi+n \cdot P_{2} \cdot \mathbb{E}\left[T P R \mid \varphi_{i t+1}<\widetilde{\varphi}\right]}{n \cdot\left(1-\delta \cdot(1-n \widetilde{\varphi})^{n-1}\right)} .
$$

Now we compute that

$$
\begin{aligned}
P_{2} \cdot \mathbb{E}\left[T P R \mid \varphi_{i t+1}<\widetilde{\varphi}\right] & =\int_{0}^{\widetilde{\varphi}} \mathbb{E}\left[T P R \mid \varphi_{i t}\right] \cdot F^{\prime}\left(\varphi_{i t}\right) d \varphi_{i t} \\
& =\int_{0}^{\widetilde{\varphi}} P_{i t} \cdot \Pi \cdot(n-1) \cdot\left(1-\varphi_{i t}\right)^{n-2} d \varphi_{i t} \\
& =\int_{0}^{\widetilde{\varphi}}\left(1-\frac{(n-1) \widetilde{\varphi}}{1-\varphi_{i t}}\right)^{n-2} \cdot \Pi \cdot(n-1) \cdot\left(1-\varphi_{i t}\right)^{n-2} d \varphi_{i t} \\
& =\int_{0}^{\widetilde{\varphi}}(n-1) \cdot \Pi \cdot\left(1-(n-1) \widetilde{\varphi}-\varphi_{i t}\right)^{n-2} d \varphi_{i t} \\
& =\Pi \cdot\left((1-(n-1) \widetilde{\varphi})^{n-1}-(1-n \widetilde{\varphi})^{n-1}\right)
\end{aligned}
$$

Substituting and rewriting yields

$$
Q=\delta \cdot \Pi \cdot \frac{n \cdot(1-(n-1) \widetilde{\varphi})^{n-1}-(n-1) \cdot(1-n \widetilde{\varphi})^{n-1}}{n \cdot\left(1-\delta \cdot(1-n \widetilde{\varphi})^{n-1}\right)} .
$$

Substituting this expression for $Q$ into the equilibrium condition

$$
\widetilde{\varphi} \cdot \Pi+Q=\Pi
$$

yields

$$
\widetilde{\varphi}+\delta \cdot \frac{n \cdot(1-(n-1) \widetilde{\varphi})^{n-1}-(n-1) \cdot(1-n \widetilde{\varphi})^{n-1}}{n \cdot\left(1-\delta \cdot(1-n \widetilde{\varphi})^{n-1}\right)}=1
$$


Finally, if $\widetilde{\varphi}=0, \varphi_{i t}<\widetilde{\varphi}$ cannot occur. Hence, the equilibrium condition boils down to $\widetilde{\varphi} \cdot \Pi+Q \geq \Pi$. Substitution of $\widetilde{\varphi}=0$ and rewriting yields $\delta \geq \frac{n}{n+1}$.

Corollary 6.8 When $\delta<\frac{n}{n+1}$, there exists no $\widetilde{\varphi}$ for which the threshold trigger strategy profile $T P R$ with private information forms a perfect Bayesian Nash equilibrium. When $\delta=\frac{n}{n+1}$, $T P R$ forms a perfect Bayesian Nash equilibrium precisely when $\widetilde{\varphi}=0$. When $\delta>\frac{n}{n+1}$, there are precisely two values of $\widetilde{\varphi}$ for which TPR forms a perfect Bayesian Nash equilibrium, namely $\widetilde{\varphi}=0$, and a unique solution $0<\widetilde{\varphi}<\frac{1}{n(n-1)}$ of the equation

$$
\varphi+\delta \cdot \frac{n \cdot(1-(n-1) \varphi)^{n-1}-(n-1) \cdot(1-n \varphi)^{n-1}}{n \cdot\left(1-\delta \cdot(1-n \varphi)^{n-1}\right)}=1 .
$$

Proof. From Theorem 6.7 we already know that for every $\delta \geq \frac{n}{n+1}$ the strategy profile $T P R$ is a Bayesian Nash equilibrium for $\widetilde{\varphi}=0$. Consider the function

$$
f(\varphi, \delta)=\delta \cdot \frac{T}{n \cdot\left(1-\delta \cdot(1-n \varphi)^{n-1}\right)}
$$

where $T=n \cdot(1-(n-1) \varphi)^{n-1}-(n-1) \cdot(1-n \varphi)^{n-1}$. From the equilibrium condition in Theorem 6.7 we know that $\varphi>0$ yields a Bayesian Nash equilibrium precisely when $f(\varphi, \delta)=$ $1-\varphi$. We show that this equation has a unique solution on the interior of interval $\left[0, \frac{1}{n}\right]$ precisely when $\delta>\frac{n}{n+1}$.

First note that $f(0, \delta)=\frac{\delta}{n(1-\delta)}$. So, at $\varphi=0$ we have $f(\varphi, \delta)>1-\varphi$ precisely when $\delta>\frac{n}{n+1}$ and $f(\varphi, \delta)=1-\varphi$ precisely when $\delta=\frac{n}{n+1}$. Further, $f\left(\frac{1}{n}, \delta\right)=\delta\left(\frac{1}{n}\right)^{n-1}<1-\frac{1}{n}$. So, at $\varphi=\frac{1}{n}$ we have $f(\varphi, \delta)<1-\frac{1}{n}$. Thus, by the fixed point Theorem of Brouwer, for $\delta \geq \frac{n}{n+1}$ there is at least one point of intersection of the respective graphs of $f(\varphi, \delta)$ and $1-\varphi$ on the interval $\left[0, \frac{1}{n}\right]$. Moreover, when $\delta>\frac{n}{n+1}$, the point of intersection is at the interior of the interval $\left[0, \frac{1}{n}\right]$. We show that the point of intersection must be unique in two steps. First we show that $f(\varphi, \delta)<1-\varphi$ on the interval $\left[\frac{1}{n(n-1)}, \frac{1}{n}\right]$. So, there are no points of intersection on the interval $\left[\frac{1}{n(n-1)}, \frac{1}{n}\right]$ and, because $f(0, \delta)>1$, there is at least one point of intersection on the interval $\left(0, \frac{1}{n(n-1)}\right)$. Then we show that $\frac{\partial f}{\partial \varphi}<-1$ on the interval $\left[0, \frac{1}{n(n-1)}\right]$, which establishes the fact that the point of intersection on the interval $\left(0, \frac{1}{n(n-1)}\right)$ is unique. Notice that

$$
\frac{\partial T}{\partial \varphi}=n \cdot(n-1)^{2} \cdot\left((1-n \varphi)^{n-2}-(1-(n-1) \varphi)^{n-2}\right) .
$$

It is easy to check that $\frac{\partial T}{\partial \varphi}<0$.

A. Consider the interval $\left[\frac{1}{n(n-1)}, \frac{1}{n}\right]$. We show that

$$
f(\varphi, \delta)<1-\varphi
$$


on this interval. Using the definition of $f(\varphi, \delta)$, it suffices to show that

$$
T<n \cdot(1-\varphi) \cdot\left(1-\delta \cdot(1-n \varphi)^{n-1}\right) .
$$

Since $\varphi \geq \frac{1}{n(n-1)}$, we know that

$$
\delta \cdot(1-n \varphi)^{n-1}<(1-n \varphi)^{n-1} \leq\left(\frac{n-2}{n-1}\right)^{n-1} .
$$

Thus, since also $\varphi \leq \frac{1}{n}$, it suffices to show that

$$
T \leq n \cdot \frac{n-1}{n} \cdot\left(1-\left(\frac{n-2}{n-1}\right)^{n-1}\right)
$$

or equivalently

$$
T \leq(n-1) \cdot\left(1-\left(\frac{n-2}{n-1}\right)^{n-1}\right) .
$$

Since $\frac{\partial T}{\partial \varphi}<0$ and $\varphi \geq \frac{1}{n(n-1)}$, we can deduce that

$$
T \leq n \cdot\left(\frac{n-1}{n}\right)^{n-1}-(n-1) \cdot\left(\frac{n-2}{n-1}\right)^{n-1} .
$$

Thus, it suffices to check that

$$
n \cdot\left(\frac{n-1}{n}\right)^{n-1}-(n-1) \cdot\left(\frac{n-2}{n-1}\right)^{n-1} \leq(n-1) \cdot\left(1-\left(\frac{n-2}{n-1}\right)^{n-1}\right)
$$

which is equivalent to

$$
n \cdot\left(\frac{n-1}{n}\right)^{n-1} \leq n-1
$$

Since $\left(\frac{n}{n-1}\right)^{n-1}$ is increasing in $n$ (monotonically converging to $e$ ), we know that $\left(\frac{n-1}{n}\right)^{n-1} \leq \frac{4}{9}$ for all $n \geq 3$. Hence

$$
n \cdot\left(\frac{n-1}{n}\right)^{n-1} \leq \frac{4}{9} n \leq n-1
$$

for all $n \geq 3$, which concludes the proof of A.

B. We show that $\frac{\partial f}{\partial \varphi}<-1$ on the interval $\left[0, \frac{1}{n(n-1)}\right]$. Notice that

$$
\begin{aligned}
\frac{\partial f}{\partial \varphi} & =\delta \cdot \frac{\frac{\partial T}{\partial \varphi} \cdot n \cdot\left(1-\delta \cdot(1-n \varphi)^{n-1}\right)-\delta \cdot T \cdot n^{2} \cdot(n-1) \cdot(1-n \varphi)^{n-2}}{n^{2} \cdot\left(1-\delta \cdot(1-n \varphi)^{n-1}\right)^{2}} \\
& =\frac{\delta \cdot \frac{\partial T}{\partial \varphi}}{n \cdot\left(1-\delta \cdot(1-n \varphi)^{n-1}\right)}-\frac{\delta^{2} \cdot T \cdot(n-1) \cdot(1-n \varphi)^{n-2}}{\left(1-\delta \cdot(1-n \varphi)^{n-1}\right)^{2}}
\end{aligned}
$$


Since $\frac{\partial T}{\partial \varphi}<0$, the first term of this expression is negative. We show that

$$
\frac{\delta^{2} \cdot T \cdot(n-1) \cdot(1-n \varphi)^{n-2}}{\left(1-\delta \cdot(1-n \varphi)^{n-1}\right)^{2}} \geq 1
$$

which is equivalent to

$$
\delta^{2} \cdot T \cdot(n-1) \cdot(1-n \varphi)^{n-2} \geq\left(1-\delta \cdot(1-n \varphi)^{n-1}\right)^{2} .
$$

Since $\delta \geq \frac{n}{n+1}, \varphi \leq \frac{1}{n(n-1)}$, and $T$ is a decreasing function, it suffices to show that

$$
\begin{aligned}
\left(\frac{n}{n+1}\right)^{2} \cdot(n-1) \cdot\left(\frac{n-2}{n-1}\right)^{n-2} & \cdot\left(n \cdot\left(\frac{n-1}{n}\right)^{n-1}-(n-1) \cdot\left(\frac{n-2}{n-1}\right)^{n-1}\right) \\
\geq & \left(1-\frac{n}{n+1} \cdot\left(\frac{n-2}{n-1}\right)^{n-1}\right)^{2}
\end{aligned}
$$

which is equivalent to

$$
\begin{aligned}
\left(\frac{n}{n+1}\right)^{2} \cdot(n-1) \cdot\left(\frac{n-1}{n-2}\right) & \cdot\left(n \cdot\left(\frac{n-2}{n}\right)^{n-1}-(n-1) \cdot\left(\frac{n-2}{n-1}\right)^{2(n-1)}\right) \\
\geq & \left(1-\frac{n}{n+1} \cdot\left(\frac{n-2}{n-1}\right)^{n-1}\right)^{2} .
\end{aligned}
$$

Since $\frac{n-2}{n} \geq\left(\frac{n-2}{n-1}\right)^{2}$, we have

$$
n \cdot\left(\frac{n-2}{n}\right)^{n-1}-(n-1) \cdot\left(\frac{n-2}{n-1}\right)^{2(n-1)} \geq\left(\frac{n-2}{n-1}\right)^{2(n-1)} .
$$

Thus, it suffices to show that

$$
\left(\frac{n}{n+1}\right)^{2} \cdot(n-1) \cdot\left(\frac{n-1}{n-2}\right) \cdot\left(\frac{n-2}{n-1}\right)^{2(n-1)} \geq\left(1-\frac{n}{n+1} \cdot\left(\frac{n-2}{n-1}\right)^{n-1}\right)^{2}
$$

which can be rewritten to

$$
n^{2} \cdot(n-1)^{2} \geq(n-2) \cdot\left((n+1) \cdot\left(\frac{n-1}{n-2}\right)^{n-1}-n\right)^{2}
$$

Now, since $\left(\frac{n-1}{n-2}\right)^{n-1} \uparrow e$ as $n \rightarrow \infty$, it suffices to show that

$$
n^{2} \cdot(n-1)^{2} \geq(n-2) \cdot((e-1) \cdot n+e)^{2}
$$

It is straightforward to verify that this inequality holds for all $n \geq 5$. Since the inequality $(*)$ also holds for $n=4$, the only remaining case is $n=3$. For this case we directly compute that 
on the interval on the interval $\left[0, \frac{1}{3}\right]$ the equation $f(\delta, \varphi)=1-\varphi$ has a unique solution $\varphi^{*}$, and that $\varphi^{*} \leq \frac{1}{6}$.

The equation $f(\varphi, \delta)=1-\varphi$ can be rewritten to $g(\varphi, \delta)=0$ with

$$
g(\varphi, \delta)=27 \delta \varphi^{3}-39 \delta \varphi^{2}+(21 \delta-3) \varphi+3-4 \delta
$$

Thus $\frac{\partial g}{\partial \varphi}=81 \delta \varphi^{2}-78 \delta \varphi+21 \delta-3$, which for $\delta>\frac{3}{4}$ is a strictly positive function on the interval $\left[0, \frac{1}{3}\right]$. So, for $\delta>\frac{3}{4}, g(\varphi, \delta)$ is strictly increasing in $\varphi$ on the interval $\left[0, \frac{1}{3}\right]$. This implies that the equation $g(\varphi, \delta)=0$ has at most one solution on the interval $\left[0, \frac{1}{3}\right]$. It is moreover straightforward to check that $g(0, \delta)=3-4 \delta<0$. Hence, by A, the equation has a unique solution $\varphi^{*}<\frac{1}{6}$.

\section{Discussion}

The results presented in the previous sections lead to the following insights. In Section 4, we show that in the presence of possible market share fluctuations a higher discount factor is required to sustain a collusive equilibrium in trigger strategies than in the absence of such fluctuations. In particular, we show that the larger the fluctuations can be, the higher the discount factor needs to be to ensure the stability of the collusive price under all circumstances. As some sort of fluctuation, albeit small, can hardly ever be denied, we should conclude that tacit collusion using trigger strategies is harder to sustain than previously accepted. In particular, it implies that in unstable markets, where for instance consumer loyalty is low, it is especially hard to sustain such a collusive equilibrium. For the same reason, collusion could break down in stable markets in which a drastic shock has occurred because of which the market shares have become unequal. The firm that has suffered most from the shock might find continuing collusive behavior unappealing because expected profits have gone down. When the discount factor is not high enough to still ensure that the overall expected value of continuing collusively outweighs the expected value of a deviation, this means that what was an equilibrium before the shock ceases to be one afterwards. This effect is possible whenever exogenous factors play a role.

When firms have full information about the realized market shares in a certain period, the market can reduce the temptation to deviate by reducing their collusive price when the firms observe that one firm's market share is (too) low. This way, an otherwise unstable collusive agreement can be kept stable, although firms enjoy lower collusive profits in some periods. However, when firms have private information about their market shares, it is unobservable to 
the other firms when this is necessary to keep collusion stable. In Section 6 it is shown that when market shares are fully observable, a range of (quasi-)collusive trigger strategy equilibria is possible. However, when firms have private information on their market share at the beginning of the period, there exist only two types of trigger strategy equilibria: the fully collusive one and one where firms play collusively as long as their market shares are above a certain bound, but deviate and start to play competitively when their market share falls below this bound. As in the latter type the competitive period will occur with probability 1 , this contributes to the explanation of price wars on the equilibrium path. Furthermore, exactly these competitive periods will make the firms' strategies harder to recognize as being part of collusive behavior.

One might think that a stable division of market shares is the result of collusive behavior by the firms in a market of homogenous goods. These results show that it is not necessarily a result of collusion but rather a stimulant of collusion. When market shares are stable and equally divided, collusion is most likely. When they are unstable or when there are firms in the market with clearly lower market shares, collusion is less likely since there is not enough to gain individually from the collusion.

Using a Bertrand type of model, we should admit that there are elements in the model which might be more extreme than we would observe in reality. In particular, in our model, the firm with the lowest price captures the entire market, even if this price is only very slightly lower than the price of its opponents. We have still chosen for this kind of model, because it is a generally accepted method to analyze tacit collusion in oligopolies and in this way we are able to show the direct effect that fluctuating market shares have on the equilibrium strategies of the competing firms. Still, it would be interesting to see what results we would get if a similar approach is taken within, for instance, a Hotelling type of model.

A point of criticism can be made at the chance mechanism used in Section 6 , which creates an independence of demand across periods. In reality we would expect that a low market share today is likely to be followed by a low market share tomorrow, which could for instance be realized by a Martingale process. We have chosen for market share realizations to be drawn from a uniform distribution, for this simplifies computations considerably while still contributes to a better understanding of the effects of fluctuating demand on the stability of collusion. In future research the model could definitely be made more realistic by choosing a chance mechanism that 
ensures a certain level of dependence of market share realizations between periods. Yet, it can be expected that the results we have found in this paper are qualitatively quite robust against this change. As said before, the main intuition behind the finding that collusion is harder to sustain when fluctuations in market share are possible is that the expected payoff from collusion goes down while the expected payoff from deviation goes up. Although this is already true with the chance mechanism we have used in this paper, this will only be strengthened when we use a chance mechanism by which a low market share today is likely to be followed by a low market share tomorrow. In that case, the expected payoff of continued collusion is even lower while the relative loss of the punishment period following a deviation is lower as well, and therefore, it is even more attractive to deviate from the collusive strategy.

Clearly there exist more equilibria in our model than the ones we have presented in this article. Some types of equilibria are certainly worth researching further if we want to investigate the consequences of fluctuating demand. An interesting type of equilibrium that could be investigated further is the possibility of firms to return to collusion after a period of competitive behavior. When there is full information on market shares this could be done by agreeing that collusion will be resumed whenever all firms have a market share above a certain level $\underline{\phi}$ after at least $T$ periods of competitive play. With private information it could be agreed that instead of having an infinite punishment period, the period of competitive play is restricted to $T$ periods, as for instance is done in Green and Porter (1984). Also "optimal" punishments like presented in Abreu, Pierce and Stacchetti (1986) can be incorporated. Finding equilibria of this type could give further aid to the research into temporary price wars along the equilibrium path.

In reality, we never see market shares that are completely equal and fixed over time. There are stronger and weaker firms, and their individual demand levels may fluctuate to a smaller or larger extent. Why this happens is often not so easy to identify when market conditions and firm characteristics appear to be stable and products seem to be homogeneous. The approach we have adopted is a step towards a model that is applicable to analyze markets in which its characteristics are not fixed and where endogenous as well as exogenous factors influence the division of demand while firms compete in prices. In all strategic situations, firms have to decide which action to take, depending on the state they find themselves in. When we acknowledge that also exogenous factors can influence which state will arise, we should indeed strive for a model that incorporates the effects of these exogenous factors in order to enhance 
our understanding of the strategic situation. It is quite likely that results that are based on static models as the original Bertrand model will change when we incorporate more dynamics and uncertainty. Our results are an indication of that.

\section{References}

[1] Abreu D, Pearce D, Stacchetti E (1986) Optimal cartel equilibria with imperfect monitoring. Journal of Economic Theory 39:251-269

[2] Athey S, Bagwell K, Sanchirico C (2004) Collusion and price rigidity. The Review of Economic Studies 71:317-349

[3] Bagwell K, Staiger RW (1997) Collusion over the business cycle. The RAND Journal of Economics 28:82-106

[4] Brander JA, Zhang A (1993) Dynamic oligopoly behavior in the airline industry. International Journal of Industrial Organization 11:407-435

[5] Domowitz I, Hubbard RG, Petersen BC (1987) Oligopoly supergames: some empirical evidence on prices and margins. The Journal of Industrial Economics 35:379-398

[6] Davidson J (1994) Stochastic Limit Theory. Advanced Texts in Econometrics series, Oxford University Press

[7] Eckert A (2004) An alternating-move price-setting duopoly model with stochastic costs. The International Journal of Industrial Organization 22:997-1015

[8] Ellison G (1994) Theories of cartel stability and the Joint Executive Committee. The RAND Journal of Economics 25:37-57

[9] Fershtman C, Pakes A (2000) A dynamic oligopoly with collusion and price wars. The RAND Journal of Economics 31:207-236

[10] Green EJ, Porter RH (1984) Noncooperative collusion under imperfect price competition. Econometrica 52:87-100

[11] Haltiwanger J, Harrington Jr. JE (1991) The impact of cyclical demand movements on collusive behavior. The RAND Journal of Economics 22:89-106

[12] Hendon E, Jacobsen HJ, Sloth B (1996) The one-shot deviation principle for sequential rationality. Games and Economic Behavior 12:274-282 
[13] Kandori M (1991) Correlated demand shocks and price wars during booms. The Review of Economic Studies 58:171-180

[14] Klemperer P (1989) Price wars caused by switching costs. The Review of Economic Studies $56: 405-420$

[15] Klemperer P (1995) Competition when consumers have switching costs: an overview with applications to industrial organization, macroeconomics and international trade. The Review of Economic Studies 62:515-539

[16] Leufkens K, Peeters R (2008) Intertemporal price competition with exogenous demand shocks. Economics Letters 99:301-303

[17] Porter RH (1983a) Optimal cartel trigger price strategies. Journal of Economic Theory $29: 313-338$

[18] Porter RH (1983b) A study of cartel stability: the Joint Executive Committee, 1880-1886. The Bell Journal of Economics 14:301-314

[19] Porter RH (1985) On the incidence and duration of price wars. The Journal of Industrial Economics 33:415-426

[20] Rotemberg JJ, Saloner G (1986) A supergame-theoretic model of price wars during booms. American Economic Review 76:390-407

[21] Scherer FM (1980) Industrial market structure and economic performance, second edition. Houghton Mifflin, Boston MA

[22] Selten R (1965) Spieltheoretische behandlung eines oligopolmodells mit nachfrageträgheit. Zeitschrift für die gesamte Staatswissenschaft 121:301-324 and 667-689

[23] Selten R (1975) Reexamination of the perfectness concept for equilibrium points. International Journal of Game Theory 4:25-55

[24] Slade ME (1989) Price wars in price-setting supergames. Economica 56:295-310

[25] Staiger RW, Wolak FA (1992) Collusive pricing with capacity constraints in the presence of demand uncertainty. The RAND Journal of Economics 23:203-220

[26] Stigler GJ (1964) A theory of oligopoly. The Journal of Political Economy 72:44-61 
[27] Wilson BJ, Reynolds SS (2005) Market power and price movements over the business cycle. The Journal of Industrial Economics 53:145-174 